\title{
Фертильность пыльцы Trollius в естественных местообитаниях и условиях культуры
}

\section{Trollius $L$. pollen fertility in situ and ex situ}

\author{
Буглова Л. В. ${ }^{1}$, Гусар А. С. ${ }^{2}$, Дзюба О. В. ${ }^{2}$, Морозова А. О. ${ }^{2}$ \\ Buglova L. V. ${ }^{1}$, Gusar A. S. ${ }^{2}$, Dziuba O. V. ${ }^{3}$, Morozova A. O. ${ }^{4}$ \\ ${ }^{1}$ ФГБУН «Центральный сибирский ботанический сад СО РАН», Новосибирск, Pоссия. E-mail: astro11@rambler.ru \\ ${ }^{2}$ ФГБОУ ВО Новосибирский государственный аграрный университет, Новосибирск, Россия. E-mail: gusara663@gmail.com; \\ dzuba009@mail.ru; helenmoroz7@gmail.com \\ ${ }^{1}$ FSIS «Central Siberian botanical garden SB RAS», Novosibirsk, Russia \\ ${ }^{2}$ FSEI HE "Novosibirsk State Agrarian University”, Novosibirsk, Russia
}

Peфepam. В статье представлены результаты определения фертильности пыльцы видов T. altaicus и T. asiaticus и их форм в природе, а так же T. apertus и T. kytmanovii из коллекции живых растений ЦСБС СО РАН. На основании полученных результатов и проделанных ранее исследований сделан вывод о нецелесообразности отнесения видов T. altaicus и T. asiaticus в разные секции.

Ключевые слова. Гибриды, популяции, фертильность пыльцы, Trollius altaicus, Trollius asiaticus.

Summary. The article presents results of determining the pollen fertility in species T. altaicus and T. asiaticus and their forms in nature, and also T. apertus and T. kytmanovii from the plants collection of the CSBG SB RAS. On the basis of the obtained results and previous studies, conclusion was made that it is not advisable to classify T. altaicus and T. asiaticus into different sections.

Key words. Hybrids, Trollius altaicus, Trollius asiaticus, pollen fertility, populations.

B семействе Ranunculaceae и, в частности, среди представителей рода Trollius L., широко pacпространена межвидовая гибридизация (Doroszewska, 1965; Малышев, 1965; Сипливинский, 1972; Зиман, 1985). Межвидовая гибридизация является важным фактором эволюции и появления новых генотипов и фенотипов, подходящих для экстремальных местообитаний (Камелин, 2009; Родионов, 2013). Геномная интрогрессия - проникновение генов одного вида в геном другого - документирована примерно у 165 видов растений (Савченко, 2009). Виток эволюционной дивергенции, на котором в данный момент находятся скрещивающиеся виды, можно определить по степени репродуктивной изоляции, которая определяется по степени фертильности пыльцы межвидовых гибридов.

Признаки T. asiaticus L.: лепестки в 2-3 раза длиннее тычинок, к верху расширенные, на верхушке заостренные; цветки крупные, до 5 см в диаметре; светлые стилодии, плодолистики 10-11 мм длины с коротким носиком 0,5-1 мм (Фризен, 1993). Исследователи рода сообщают о высоком полиморфизме данного рода и к нему же относят растения с чуть более короткими лепестками, короче чашелистиков не более чем на 5 мм, узкими, округлыми на вершине (Шипчинский, 1937; Сипливинский, 1972; Doroszewska, 1974).

K T. altaicus C. А. Меу. относятся растения с одиночными цветками диаметром 4 см; чашелистики в числе 10-20 штук, золотисто-желтые или оранжевые снаружи, иногда красноватые. Лепестки около 11 мм длины линейные с тупой или округлой верхушкой, оранжевые. Носик около 3 мм длины, черно-фиолетовый, искривленный (Фризен, 1993).

По классификации А. Doroszewska (1974) T. asiaticus относится к секции Longipetala Doroz., T. altaicus принадлежит секции Trollius Doroz., что дает право предполагать, что автор имела в виду наличие репродуктивной изоляции между ними. 
Для территории Горного Алтая установлено наличие высотной полосы, на которой произрастают гибриды между этими видами (Буглова, 2018). Растения из таких популяций обладают промежуточными диагностическими признаками или различными комбинациями признаков от родительских видов. На основании морфологического анализа популяций было высказано предположение о беккроссах (T. asiaticus х T. altaicus x T. altaicus) при происхождении форм T. altaicus с темноокрашенными стилодиями и лепестками, превышающими по длине тычинки (Буглова, 2018).

Целью данной работы является оценка фертильности пыльцы T. asiaticus и T. altaicus из природных популяций включая их морфологические формы и растения из полосы естественной гибридизации, а так же трех видов из сибирского региона в условиях культуры.

\section{Методы и материалы}

Проанализирована пыльца с 46 гербарных листов из 34 пунктов сбора материала. Большая часть гербарных образов T. altaicus, T. asiaticus и их форм собрана на территории Горного Алтая из Кош-Агачского, Онгудайского, Усть-Канского, Усть-Коксинского, Улаганского, Чемальского районов; единичные сборы выполнены на территории Солонешенского района Алтайского края, Маслянинского и Искитимского районов Новосибирской области. Растения T. asiaticus из природных окрестностей ЦСБС пересажены в биоресурсную научную коллекцию УНУ (USU № 440534), затем собраны в гербарий. T. apertus Perfil. ex Igoschina получен из Ботанического сада города Киров, выращен в коллекции USU № 440534, собран в гербарий. Цветущие побеги T. kytmanovii Reverd. из Иркутской области, хребет Хамар-Дабан, по берегу реки Снежной собраны в гербарий, растения пересажены в коллекцию УHУ USU № 440534, затем собраны в гербарий (табл.).

В каждой природной популяции было изучено от 1 до 6 растений (выборка), пыльца извлекалась из гербарных образцов не старше 9 лет. Распределение растений из природных популяций по морфологическим формам и гибридам выполнено на основании предыдущих исследований (Буглова, 2018; Буглова, Жирова, 2019).

В качестве показателя фертильности пыльцевых зерен использована йодная реакция на крахмал (Барыкина и др., 2004). По интенсивности окрашивания пыльцевых зерен реактивом IKI составлена таблица 1. Микроскопирование выполнено на Primo Star фирмы Zeiss; пыльцу подсчитывали в 5 полях зрения. Окраска пыльцевых зерен была разбита на четыре диапазона в зависимости от ее интенсивности, оцениваемой визуально: $0-0,25 ; 0,25-0,50 ; 0,50-0,75 ; 0,75-1$. Количество окрашенных пыльцевых зерен представлено в процентах от общего числа.

\section{Результаты и обсуждение}

Для большинства изученных растений характерна высокая фертильность пыльцы (табл.). Доля пылинок с интенсивностью окрашивания IKI в зоне 0,75-1 колеблется от 60 до 97 \%. Это означает, что пыльца богата крахмалом для роста пыльцевой трубки. Виды T. asiaticus и T. apertus имеют фертильную пыльцу и в условиях культуры. Это свидетельствует об их успешной адаптации.

У T. kytmanovii, интродуцированных на коллекционном участке, наблюдается значительное снижение качества пыльцы по сравнению с пыльцой растений этого же вида в естественной среде обитания. Это объясняется стрессовыми условиями континентального климата новосибирской области, неестественными для представителей этого вида. Однако доля фертильной пыльцы с интенсивностью окраски 50-100 \% составляет 65,52\% от общего количества, что является, по нашему мнению, достаточным для успешного опыления.

Также хорошими показателями фертильности пыльцы обладают растения из популяций, выделенных в предыдущей работе как гибридные между T. asiaticus и T. altaicus по наличию экземпляров с признаками обоих видов (Буглова, 2018). Это свидетельствует об отсутствии репродуктивно-генетической изоляции видов T. asiaticus и T. altaicus. Низким показателем фертильности обладает всего один гибридный образец, отобранный на Семинском перевале республики Алтай (табл.). Предположительно, причиной низкого качества пыльцы этого образца может являться высокая рекреационная нагрузка данной местности. 
Таблица

Процентная доля пыльцы сибирских видов Trollius по интенсивности окрашивания JKJ

\begin{tabular}{|c|c|c|c|c|c|}
\hline \multirow{2}{*}{ Вид, Место сбора } & \multirow{2}{*}{$\mathrm{n}^{*}$} & \multicolumn{4}{|c|}{ Окрашивание IKI, \% } \\
\hline & & $0-0,25$ & $0,25-0,5$ & $0,5-0,75$ & $0,75-1$ \\
\hline \multicolumn{6}{|c|}{ T. altaicus } \\
\hline $\begin{array}{l}\text { Кош-Агачский р-н, } 49.67 \text { N; } 88.02 \text { E; h- } 2050 \text { м над } \\
\text { ур. м. }\end{array}$ & 1 & 1,69 & 3,51 & 13,38 & 81,43 \\
\hline \multirow{4}{*}{$\begin{array}{l}\text { Усть-Коксинский р-н, пер. Кырлыкский; } 50.66 \text { N; } 84.98 \\
\text { Е; h - } 1460 \text { м над ур. м. }\end{array}$} & 1 & 2,05 & 3,85 & 27,18 & 66,92 \\
\hline & 2 & 4,24 & 0 & 21,19 & 74,58 \\
\hline & 3 & 2,86 & 7,01 & 22,6 & 67,53 \\
\hline & 4 & 1,83 & 2,19 & 23,72 & 72,26 \\
\hline $\begin{array}{l}\text { Усть-Канский р-н, пер. Карагайский } 50.40 \text { N; } 84.47 \text { E; } \\
\text { h -1640 м над ур. м. }\end{array}$ & 1 & 12,37 & 37,11 & 48,45 & 2,06 \\
\hline $\begin{array}{l}\text { Кош-Агачский р-н ,p. Джазатор; 49,64 N; 87,83 E; h - } \\
1790 \text { м над ур. м. }\end{array}$ & 1 & 25,58 & 1,79 & 30,05 & 42,58 \\
\hline $\begin{array}{l}\text { Усть-Коксинский р-н, Мараловодка-г. Красная; } 50.16 \text { N; } \\
85.37 \text { E h - } 1530 \text { м над ур. м. }\end{array}$ & 1 & 0,94 & 2,19 & 10,35 & 86,52 \\
\hline $\begin{array}{l}\text { Онгудайский р-н, Онгудайский р-н, г. Тады-Куш; } 50.66 \\
\text { N; } 85.7 \text { E; h-1950 м над ур. м. }\end{array}$ & 1 & 1,68 & 0,84 & 26,89 & 70,59 \\
\hline $\begin{array}{l}\text { г. Тады-Куш; } 50.00 \text { N; } 85.80 \text { E; h-1800-1850 м над } \\
\text { ур. м. }\end{array}$ & 1 & 1,10 & 0 & 0 & 98,90 \\
\hline Улаганский p-н, 50.33 N; 87.74 E; h-2590 м над ур. м. & 1 & 5,56 & 1,39 & 2,78 & 90,28 \\
\hline \multicolumn{6}{|c|}{$\begin{array}{l}\text { T. altaicus с длинными лепестками } \\
\end{array}$} \\
\hline \multirow{3}{*}{$\begin{array}{l}\text { Кош-Агачский р-н, М. Ак-Тру } 50.07 \text { N; } 87.77 \text { E; h-- } \\
2240 \text { м над ур. м. }\end{array}$} & 1 & 12,29 & 5,17 & 48,71 & 33,84 \\
\hline & 2 & 6,98 & 3,49 & 22,09 & 67,44 \\
\hline & 3 & 0,27 & 0 & 8,31 & 91,42 \\
\hline $\begin{array}{l}\text { Улаганский р-н, оз. Чейбеккель; } 50.39 \text { N; } 87.62 \text { Е; } \\
\text { h-1810 м над ур. м. }\end{array}$ & 1 & 6,14 & 11,7 & 36,55 & 45,61 \\
\hline \multirow{2}{*}{$\begin{array}{l}\text { Улаганский р-н, ок. оз. Узункель; } 50.49 \text { N; } 87.64 \text { E; h - } \\
2030 \text { м над ур. м. }\end{array}$} & 1 & 32,00 & 0 & 16,00 & 52,00 \\
\hline & 1 & 6,54 & 1,92 & 6,15 & 85,39 \\
\hline $\begin{array}{l}\text { Улаганский р-н, окр. «Красные ворота» 9-й км; } 50.37 \text { N; } \\
87.63 \text { E; h -1760 м над ур. м. }\end{array}$ & 1 & 1,06 & 0,18 & 1,41 & 97,36 \\
\hline $\begin{array}{l}\text { Усть-Канский р-н, p. Угар; } 50.83 \text { N; } 85.25 \text { E; h -1300 м } \\
\text { над ур. м. }\end{array}$ & 1 & 1,72 & 9,36 & 18,23 & 70,69 \\
\hline \multicolumn{6}{|c|}{ популяции с гибридными растениями T. altaicus $\times$ T. asiaticus } \\
\hline \multirow{6}{*}{$\begin{array}{l}\text { Онгудайский р-н, пер. Семинский (стелла); } 51.04 \text { N; } \\
85.60 \text { E; h - } 1740 \text { м над ур. м. }\end{array}$} & 1 & 1,86 & 1,86 & 27,66 & 68,62 \\
\hline & 2 & 1,33 & 4,86 & 3,53 & 90,29 \\
\hline & 3 & 1,92 & 8,65 & 2,56 & 86,86 \\
\hline & 4 & 15,84 & 46,49 & 31,20 & 6,49 \\
\hline & 5 & 17,28 & 2,81 & 14,90 & 65,01 \\
\hline & 6 & 0,91 & 4,36 & 9,44 & 85,30 \\
\hline $\begin{array}{l}\text { Кош-Агачский р-н, окр. Д. Беляши } 49.72 \text { N; } 87.43 \text { E; } \\
\text { h - } 1620 \text { м над ур. м. }\end{array}$ & 1 & 8,71 & 29,02 & 53,83 & 8,44 \\
\hline \multirow{3}{*}{$\begin{array}{l}\text { Усть-Канский р-н, Ябоганский пер., } 50.52 .34 \text { N, } \\
85.14 .18 \text { E; h-1480 м над ур. м. }\end{array}$} & 1 & 5,28 & 14,85 & 20,13 & 59,74 \\
\hline & 2 & 2,22 & 0,55 & 4,43 & 92,80 \\
\hline & 3 & 0 & 7,16 & 27,34 & 65,51 \\
\hline $\begin{array}{l}\text { Усть-Канский р-н, зап. подножье Ябоганского пер., } \\
50.89 \text { N; } 85.20 \text { E; h-1200 м над ур. м. }\end{array}$ & 1 & 2,06 & 1,03 & 19,24 & 77,66 \\
\hline \multirow{2}{*}{ Онгудайский p-н; 51.02 N; 85.62 E; h -1580 м над ур. м. } & 1 & 0,35 & 4,51 & 12,15 & 82,99 \\
\hline & 2 & 9,68 & 3,81 & 25,81 & 60,70 \\
\hline Онгудайский р-н; 51.02 N; 85.62 E; h -1700 м над ур. м. & 1 & 24,21 & 5,26 & 12,63 & 57,9 \\
\hline Онгудайский р-н; 50.62 N; 85.77 E; h -1425 м над ур. м. & 1 & 0,53 & 0 & 28,27 & 71,20 \\
\hline
\end{tabular}


Таблица (окончание)

\begin{tabular}{|c|c|c|c|c|c|}
\hline \multirow{2}{*}{ Вид, Место сбора } & \multirow{2}{*}{$\mathrm{n}^{*}$} & \multicolumn{4}{|c|}{ Окрашивание IKI, \% } \\
\hline & & $0-0,25$ & $0,25-0,5$ & $0,5-0,75$ & $0,75-1$ \\
\hline \multicolumn{6}{|l|}{ T. asiaticus с длинными стилодиями } \\
\hline $\begin{array}{l}\text { Чемальский р-н, окр. Усть-Семы; } 51.64 \text { N; } 85.76 \text { E; h- } \\
400 \text { м над ур. м. }\end{array}$ & 1 & 1,25 & 1,88 & 10,35 & 86,52 \\
\hline $\begin{array}{l}\text { Онгудайский р-н. } 302 \text { км, } 50.84 \text { N; } 85.68 \text { E; h-950 м над } \\
\text { ур. м. 12.06.15. }\end{array}$ & 1 & 3,61 & 1,81 & 12,65 & 81,93 \\
\hline $\begin{array}{l}\text { Онгудайский р-н; пер. Чике-Таман; } 50.64 \text { N; } 86.31 \text { E; h- } \\
1300 \text { м над ур. м. }\end{array}$ & 1 & 0,23 & 13,09 & 10,84 & 75,85 \\
\hline $\begin{array}{l}\text { Усть-Канский р-н, пер. Келейский; } 51.13 \text { N; } 84.76 \text { E; h - } \\
1300 \text { м над ур. м. }\end{array}$ & 1 & 1,69 & 7,97 & 17,63 & 72,71 \\
\hline $\begin{array}{l}\text { Усть-Канский р-н, пер. Кукуя; } 51.44 \text { N; } 85.22 \text { E; h-1250 } \\
\text { м над ур. м. }\end{array}$ & 1 & 2,15 & 6,03 & 10,33 & 81,49 \\
\hline $\begin{array}{l}\text { Усть-Коксинский р-н, Маральник-2 } 50.43 \text { N; } 84.83 \text { E; } \\
\text { h - } 890 \text { м над ур. м. }\end{array}$ & 1 & 2,56 & 0,28 & 25,85 & 71,31 \\
\hline $\begin{array}{l}\text { Алтайский край, Солонешенский район; } 51.82 \text { N; } 84.40 \\
\text { Е h -510 м над ур. м. }\end{array}$ & 1 & 5,00 & 0 & 15,83 & 79,17 \\
\hline \multicolumn{6}{|l|}{ T. asiaticus } \\
\hline \multirow{2}{*}{$\begin{array}{l}\text { Кош-Агачский р-н., хр. Чихачева } 50.08 \text { N; } 89.42 \text { E; h - } \\
2450 \text { м над ур. м. }\end{array}$} & 1 & 1,58 & 15,79 & 57,37 & 25,26 \\
\hline & 2 & 1,14 & 5,46 & 25,23 & 68,18 \\
\hline $\begin{array}{l}\text { Новосибирская обл., Маслянинский р-н.,. ок. р. Суенга; } \\
54.43 \text { N; } 84.54 \text { Е; h- } 190 \text { м над ур. м. }\end{array}$ & 1 & 1,76 & 0 & 18,24 & 80,00 \\
\hline \multirow{3}{*}{$\begin{array}{l}\text { Новосибирская обл., Искитимский р-н, } 54.52 \text { N; } 83.63 \text { E; } \\
\text { h - } 140 \text { м над ур. м. }\end{array}$} & 1 & 4,58 & 2,29 & 15,26 & 77,48 \\
\hline & 2 & 3,00 & 0,16 & 2,37 & 94,48 \\
\hline & 3 & 4,86 & 4,05 & 39,71 & 51,38 \\
\hline \multicolumn{6}{|c|}{ Растения из коллекции и из природы } \\
\hline $\begin{array}{l}\text { T. kytmanovii, Иркутская обл., р. Снежная, } 26.06 .04 \text { - } \\
\text { природа }\end{array}$ & 1 & 3,39 & 0 & 5,09 & 91,53 \\
\hline T. kytmanovii, коллекция ЦСБС, р. Снежная, & 1 & 31,72 & 2,76 & 28,97 & 36,55 \\
\hline T. apertus, из Бот. сада г. Киров, коллекционный участок & 1 & 23,13 & 2,72 & 3,06 & 71,09 \\
\hline T. asiaticus, ЦСБС, коллекционный участок & 1 & 2,11 & 1,06 & 1,48 & 95,36 \\
\hline
\end{tabular}

Примечание: * - выборка, растения из одной популяции.

Таким образом, фертильность пыльцы в природных популяциях T. altaicus и T. asiaticus L. достаточно высокая. Для этих видов характерны существенные морфологические различия при отсутствии репродуктивной изоляции на генетическом уровне, что подтверждается не только высокими показателями фертильности пыльцы у растений из гибридных популяций. Учитывая данные ISSR-маркирования, подтверждающие наличие близкого генетического родства с интрогрессией этих видов (Буглова, Нуждина, 2018), мы считаем разделение их в разные секции, выполненное A. Doroszewska (1974), необоснованным. Состав секций, выполненный ею на основании морфологического признака длины лепестков, требует дальнейшего переосмысления.

Благодарности. Работа выполнена по государственному проекту VI.52.1.3. «Выявление путей адаптации растений к контрастным условиям обитания на популяционном и организменном уровнях» № AAAA-A17-117012610053-9. С 2009 по 2014 гг. исследования были поддержаны экспедиционными грантами Сибирского Отделения РАН. Авторы выражают искреннюю благодарность О. С. Жировой за ценные советы и рекомендации по ходу написания статьи. 


\section{ЛИТЕРАТУРА}

Барыкина Р. П., Веселова Т. Д., Девятов А. Г., Джслилова Х. Х., Ильина Г. М., Чубатова Н. В. Справочник по ботанической микротехнике. Основы и методы. - М.: Изд-во МГУ, 2004. - 312 с.

Буглова Л. В., Нуждина Н.С. Изучение генетического разнообразия представителей рода Trollius (Ranunculaceae) с помощью ISSR-маркеров // Растительный мир Азиатской России, 2018. - № 2(30). - C. 66-75. DOI: 10.21782/RMAR1995-2449-2018-2(66-75)

Буглова Л. В. Естественные гибриды Trollius asiaticus х T. altaicus: признаки и распространение // Проблемы ботаники Южной Сибири и Монголии: Сб. науч. ст. по материалам XVII междунар. науч.-практ. конф. (24-27 мая 2018 г., Барнаул). - Барнаул: Изд-во АлтГУ, 2018. - С. 180-183.

Буглова Л. В., Жирова О. С. Изменчивость диагностически значимых признаков у видов Trollius asiaticus и T. altaicus (Ranunculaceae) // Бот. журн., 2019. - № 1. (принята к печати)

Зиман С. Н. Морфология и филогения семейства лютиковых. - Киев: Наукова думка, 1985. - 248 с.

Игошина К. Н. О видах рода Trollius на Полярном Урале // Бот. журн., 1968. - Т. 53, № 6. - С. 779-794.

Камелин Р. В. Особенности видообразования у цветковых растений // Труды Зоологического института РАН, 2009. - Приложение № 1. - С. 141-149.

Малышев Л. И. Высокогорная флора Восточного Саяна. Обзор сосудистых растений, особенности состава и флорогенезис. - М.-Л.: Наука, 1965. - 368 с.

Родионов $\boldsymbol{A}$. В. Полиплоидия и межвидовая гибридизация в эволюции цветковых растений // Вавиловский журнал генетики и селекции, 2013. - Т. 17, № 4/2. - С. 916-928.

Савченко В. К. Геогеномика: организация биосферы. - Минск: Беларус. наука, 2009. - 415 с.

Сипливинский В. H. Род Trollius L. на севере и востоке Азии // Новости систематики высших растений, 1972. - Вып. 9. - С. 163-182.

Фризен Н. В. Trollius L. - жарок, или купальница // Флора Сибири. - Т. 6. - Новосибирск: Наука, 1993. - С. 103-108.

Шипчинский Н. В. Купальница - Trollius L. // Флора СССР. Т. 7. - М.-Л.: Изв. Ак. Наук СССР, 1937. - С. $42-53$.

Doroszewska A. The genus Trollius L. A taxonomical study // Monogr. bot., 1974. - Vol. 41. - P. 1-184.

Li L. Q., Tamura M. Trollius L. // Flora of China. - Beijing, 2001. - Vol. 6. - P. 137-142. 